\title{
Pemanfaatan Turbin Ventilator sebagai Pembangkit Listrik Alternatif
}

\author{
Aris Suryadi' ${ }^{1}$, Purwandito Tulus Asmoro's), Roja Raihan ${ }^{3)}$ \\ 1,2,3) Politeknik Enjinering Indorama, Purwakarta, \\ Telp. +62-264-202312 Fax. +62-264-202318 Mobile. 08197508012 \\ Website: www.pei.ac.id, E-mail: aris.suryadi@pei.ac.id \\ SINTA ID : 5999057 ORCID : 0000-0002-0742-8347
}

\begin{abstract}
Abstrak
Indonesia sedang giatnya mengembangkan potensi energi terbarukan sebagai pengganti cadangan energi fosil yang menipis. Energi angin merupakan energi yang bersih tanpa mencemari lingkungan. Energi angin di Indonesia sangat berpotensi besar, tetapi masih kurang maksimal untuk pemanfaatannya. Salah satu bentuk energi alternatif yang dapat dimanfaatkan sebagai energi mekanik oleh turbin angin untuk mengubah menjadi energi listrik oleh generator dc. Ventilator yang beroperasi selama 24 jam berfungsi mengisap udara dan, terletak diatap gudang, gedung olahraga.. Pemanfaatan angin agar menjadi energi listrik, dirancang dari penggunaan turbin ventilator sebagai media pengubah angin menjadi energi gerak, dimana pergerakan turbin diteruskan oleh perbandingan pulley dan v-belt ke generator, generator inilah yang menghasilkan energi listrik. Penelitian ini menguji seberapa besar energi listrik yang dihasilkan pada perbedaan kecepatan angin mulai dari 3 hingga 5,4 $\mathrm{m} / \mathrm{s}$. Dari pengujian yang dilakukan, putaran generator, dan tegangan terendah terdapat pada kecepatan angin 3 $\mathrm{m} / \mathrm{s}$ yaitu sebesar 3,6 V. sedangkan putaran generator, dan tegangan yang tertinggi didapatkan jika kecepatan angin adalah $5,4 \mathrm{~m} / \mathrm{s}$ yaitu sebesar $10,3 \mathrm{~V}$.
\end{abstract}

Kata kunci: energi angin, generator dc, turbin ventilator

\section{Abstract}

Indonesia is actively developing the potential for renewable energy as a substitute for depleting fossil energy reserves. Wind energy is clean energy without polluting the environment. Wind energy in Indonesia has great potential, but it is still not optimal enough for its utilization. One form of alternative energy that can be utilized as mechanical energy by wind turbines to convert into electrical energy by dc generators. Ventilators that operate for 24 hours function to suck air and, located on the roof of a warehouse, sports hall .. Utilization of wind to become electrical energy, is designed from the use of a ventilator turbine as a medium to convert wind into motion energy, where the movement of the turbine is continued by pulley and v-belt comparisons to the generator, this generator produces electricity. This research examines how much electrical energy is produced at different wind speeds ranging from 3 to $5.4 \mathrm{~m} / \mathrm{s}$. From the tests conducted, the generator rotation, and the lowest voltage is at wind speed of $3 \mathrm{~m} / \mathrm{s}$ which is $3.6 \mathrm{~V}$. while the generator speed and the highest voltage is obtained if the wind speed is $5.4 \mathrm{~m} / \mathrm{s}$ which is $10.3 \mathrm{~V}$.

Key word: dc generator, turbine ventilator, wind energy.

\section{PENDAHULUAN}

Kebutuhan akan energi di dunia pada umumnya dan Indonesia khususnya terus meningkat karena, pertumbuhan ekonomi dan konsumsi energi akibat pertambahan penduduk. Angin merupakan salah satu sumber daya alam berpotensi sebagai energi alternatif dan ramah lingkungan serta bersifat terbarukan sehingga peluang besar untuk pengembangan [1], [2].

Untuk mengubah energi kinetik pada angin menjadi energi listrik diperlukan turbin angin. Dengan memanfaatkan energi angin tersebut sebagai penggerak pada turbin ventilasi yang sering digunakan dan terletak di atap bangunan yang berfungsi sebagai ventilasi bangunan perumahan dan industri [2], [3].

\section{LANDASAN TEORI}

\subsection{Sistem Konversi Energi Angin}

Merupakan suatu sistem yang bertujuan untuk mengubah energi angin menjadi energi mekanik poros oleh rotor yang diubah oleh generator menjadi energi listrik. Besarnya energi yang dapat diubah ke rotor tergantung pada kecepatn angin, luas area, dan kerapatan udara [3].

Energi kinetik angin yang berhembus dalam satuan waktu adalah: 


$$
P_{w}=\frac{1}{2} \rho A v^{3}
$$

Keterangan :

$$
\begin{aligned}
P_{w} & : \text { Daya angin }(\mathrm{W}) \\
v & : \text { Kecepatan angin }(\mathrm{m} / \mathrm{s}) \\
A & : \text { Luas penampang }\left(\mathrm{m}^{2}\right) \\
\rho & : \text { Kerapatan udara }\left(1.1726 \mathrm{~kg} / \mathrm{m}^{3}\right)
\end{aligned}
$$

\subsection{Turbin Ventilator}

Merupakan alat yang berfungsi mensirkulasikan udara di dalam ruangan seperti roof fan. Berbeda halnya dengan kipas angin seperti exhaust fan yang memerlukan daya listrik sedangkan turbin ventilator digerakkan oleh hembusan angin [4].

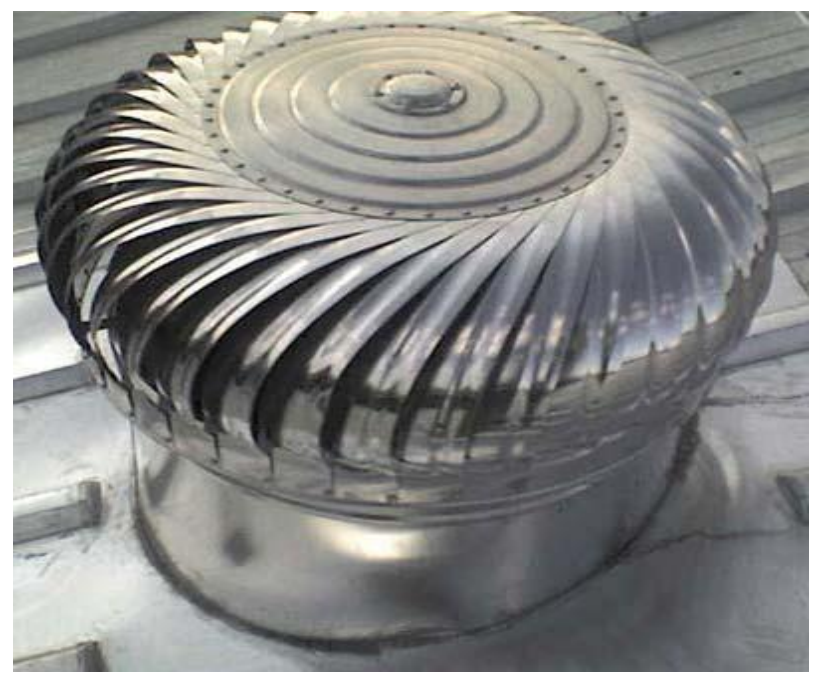

Gambar 1 Turbin ventilator[4]

\subsection{Prinsip Kerja Turbin Ventilator}

Hembusan angin yang lemah sekalipun atau angin kecepatan tinggi dapat memutarkan sirip sehingga udara dalam ruangan dapat keluar. Hal ini terlihat pada Gambar 2. Turbin ventilator yang terpasang dengan hembusan angin di lingkungannya mampu mengeluarkan udara panas dari dalam ruangan serta mampu mengalir naik dan menekan keluar melalui sirip-sirip [5].

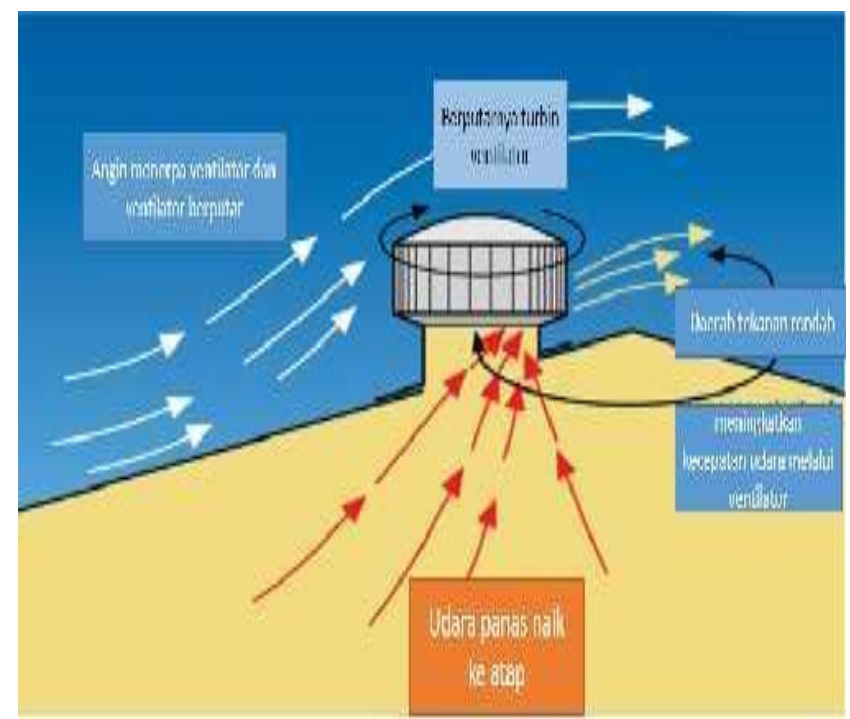

Gambar 2 Prinsip kerja turbin ventilator[5]

\subsection{Generator DC sebagai pembangkit listrik}

Merupakan mesin listrik yang mengubah energi mekanis menjadi energi listrik serta menghasilkan arus DC. Generator DC hanya memiliki satu cincin yang terbelah ditengahnya dan dinamakan komutator [6]-[8]. Adapun bentuk fisik dari generator DC untuk pembangkitan listrik diperlihatkan pada Gambar 3.

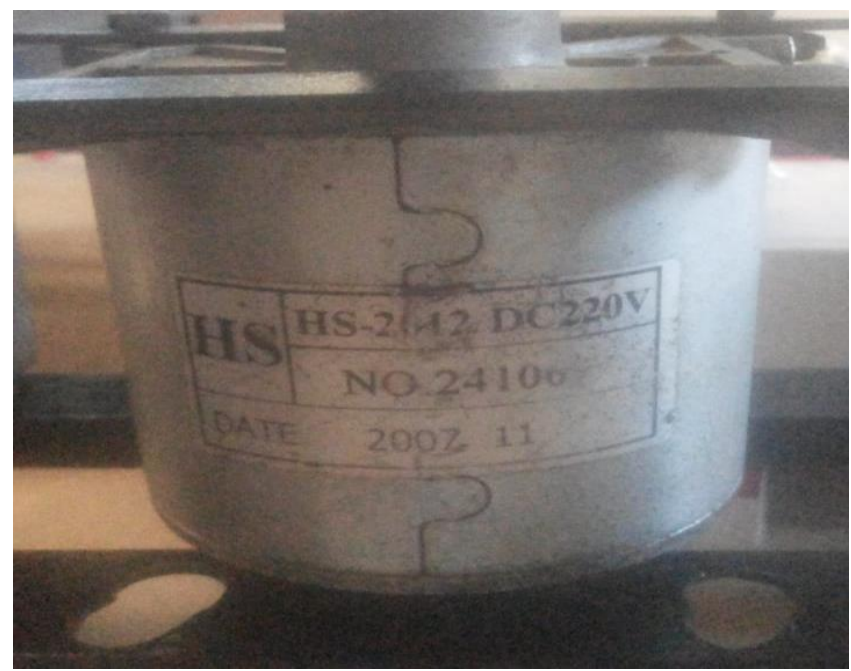

Gambar 3 Generator DC

Pembangkit listrik yang menggunakan angin sebagai sumber energi untuk menghasilkan energi listrik. Untuk menentukan turbin angin atau kapasitas turbin yang akan digunakan untuk pemilihan pembangkit dinyatakan dengan persamaan:

$$
\mathrm{P}=\mathrm{P}_{\text {tpem } \mathrm{X}}(100 / x)
$$

Dimana:

$\mathrm{P}=$ kapasitas turbin

$\mathrm{P}_{\mathrm{tpem}}=$ kapasitas turbin pemasok

$\mathrm{x}=$ efisiensi kecepatan angin

Sedangkan efisiensi kecepatan angin sebagai berikut:

$$
\mathrm{X}=\text { (rerata kec. angin / kec. angin maks }) \times 100 \%
$$

\subsection{Charger Controller (CC)}

Merupakan komponen elektronik yang digunakan untuk mengatur arus searah serta mengatur tegangan yang masuk menuju accumulator agar tegangan tetap stabil dengan tujuan tidak terjadi over charging atau over voltage. CC dikategorikan baik jika mampu mendeteksi kapasitas accumulator, apabila kapasitas accumulator terisi penuh maka secara otomatis pengisian pada accumulator dari panel akan diputus. 


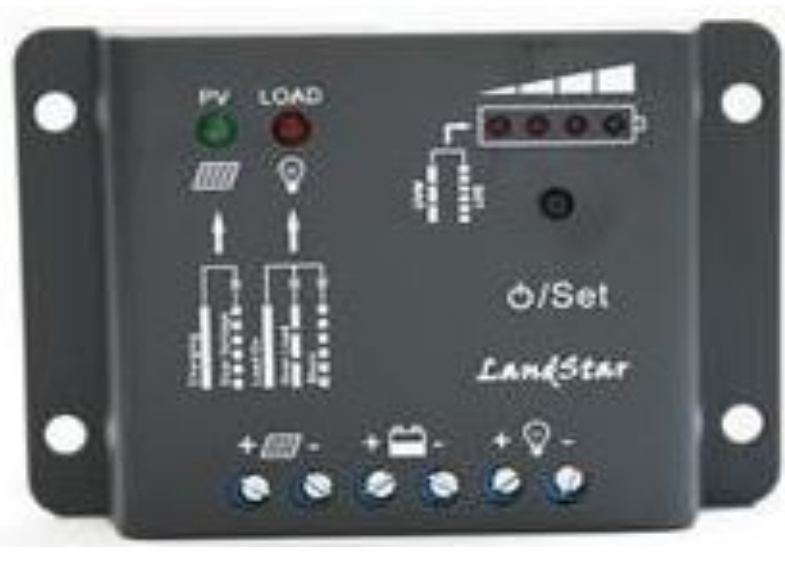

Gambar 4 Charger Controller (SCC)

\subsection{Accumulator}

Merupakan komponen yang berfungsi penyimpan energi listrik dan dapat diisi (charge). Pengisian ini menggunakan rangkaian rectifier (charging) berfungsi mengubah arus AC menjadi DC serta tegangan keluaran disesuaikan pada accumulator serta besarnya arus dan tegangan pada pengisian sangat menentukan kondisinya [9].

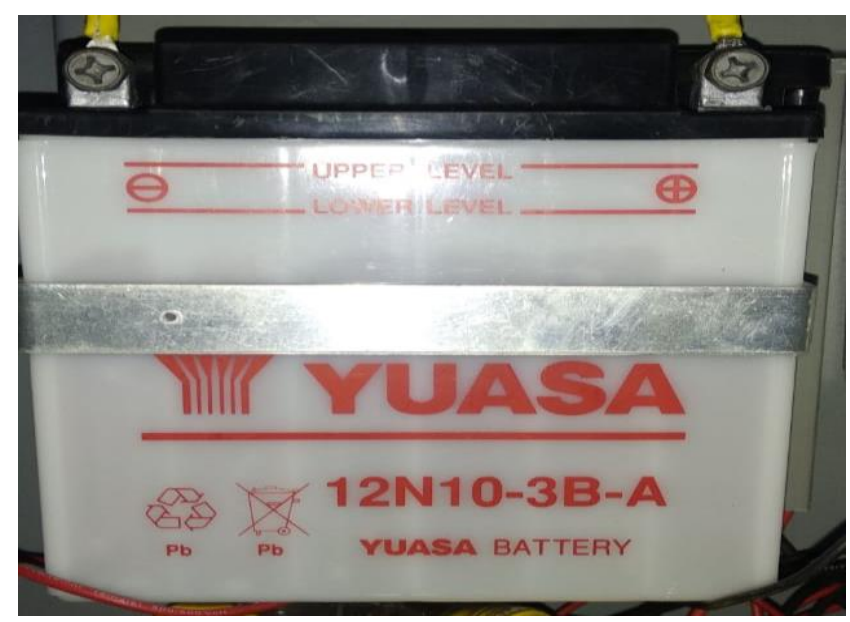

Gambar 5 Accumolator [9]

\section{METODOLOGI PENELITIAN \\ 3.1 Tahapan Penelitian}

Merupakan tahapan yang dimulai dengan mempelajari literatur dan dilanjutkan dengan survei untuk dua lokasi yang berbeda yakni lokasi di depan gedung laboratorium Prodi Teknologi Listrik, dan lokasi ke dua di daerah taman dekat gedung Vocational Training Center, Politeknik Enjinering Indorama serta melakukan pengukuran kecepatan angin yang ada. Tahap kedua adalah memilih ventilator dan merancang dudukannya, menentukan kebutuhan rangkaian pengendali, inverter dan pemilihan accumulator. Tahap ke tiga melakukan evaluasi rancangan sistem selanjutnya tahap keempat melakukan pengukuran dan uji coba kelayakan perangkat apakah sudah sesuai dengan perancangan dan menghasilkan daya yang direncanakan.
Perakitan alat yang terealisasikan selanjutnya dilakukan pengujian pada alat tersebut, apabila alat mengalami kendala dengan rencana awal maka dilakukan perbaikan pada titik yang menjadi kendala dengan mengulang proses perakitan alat. Sedangkan apabila alat telah sesuai dengan rencana dan tidak ada kendala, maka dilakukan proses pengambilan data pengukuran kecepatan angin putaran rotor, arus, tegangan serta fungsi kenerja alat. Setelah pengambilan data pengukuran selanjutnya melakukan analisa data dan serta membuat simpulan dari hasil analisa. Adapun alur metode penelitian tersebut diperlihatkan pada Gambar 6.

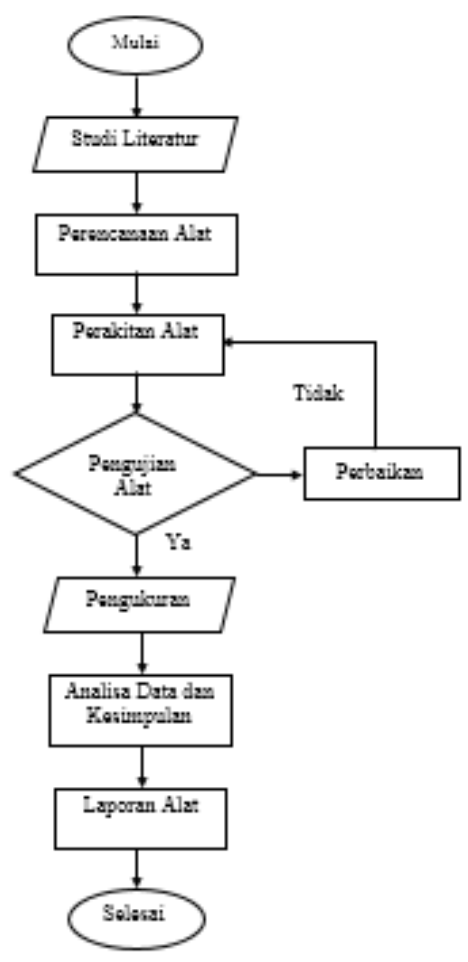

Gambar 6 Alur Metode Penelitian

\subsection{Waktu dan Tempat Penelitian}

Lamanya penelitian yang telah dilakukan dalam waktu 5 bulan, dimulai dari penandatangan kontrak penelitian. Lokasi penelitian untuk menguji alat yang telah dilakukan pada dua lokasi yaitu di depan gedung laboratorium (lokasi A), Prodi Teknologi Listrik dan di depan gedung Vocational Training Center (lokasi B), Politeknik Enjinering Indorama. 


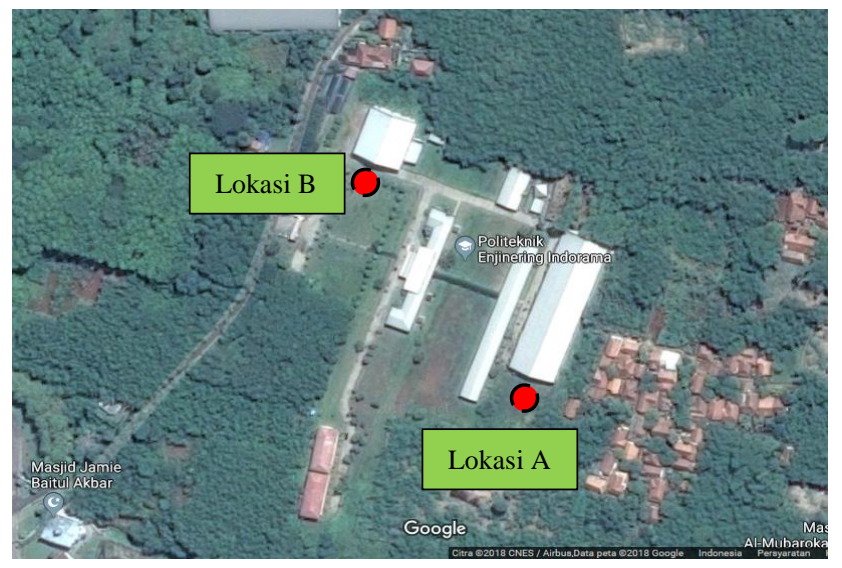

Gambar 7 Lokasi pengukuran angin di Politeknik Enjinering Indorama ( $107^{\circ} 25^{\prime} 06,0$ ' Bujur Timur dan $6^{\circ} 33$ '12,1" Lintang Selatan )

\section{HASIL DAN PEMBAHASAN}

Dari hasil survei dua lokasi tersebut, lokasi B yang merupakan kondisi angin yang mempunyai potensi angin untuk pembangkitan listrik. Setelah menentukan potensi angin pada lokasi B maka didapatkan hasil pengukuran untuk pengujian tanpa beban seperti terlihat pada Tabel 1 seperti dibawah ini.

Tabel 1 Pengukuran tanpa beban di lokasi B

\begin{tabular}{ccccc}
\hline \multicolumn{5}{c}{ Pengujian Tanpa Beban } \\
\hline $\begin{array}{c}\text { Kec. } \\
\text { Ukur } \\
\text { ke- }\end{array}$ & $\begin{array}{c}\text { Angin } \\
(\mathrm{m} / \mathrm{s})\end{array}$ & Teg. & Arus & $\begin{array}{c}\text { Put. } \\
\text { Gen. }\end{array}$ \\
& & & & \\
& & & & \\
\hline 1 & 5,3 & 10,4 & 0 & 159 \\
2 & 5,3 & 10,3 & 0 & 157 \\
3 & 5,3 & 8,6 & 0 & 147 \\
4 & 5 & 8,6 & 0 & 133 \\
5 & 4,9 & 8,5 & 0 & 128 \\
6 & 4,8 & 4,9 & 0 & 113 \\
7 & 3,5 & 4,8 & 0 & 90 \\
8 & 3,4 & 4,7 & 0 & 77 \\
9 & 3,4 & 4,2 & 0 & 74 \\
10 & 3 & 3,6 & 0 & 70 \\
\hline Rata" & 4,39 & 6,86 & 0 & 115 \\
\hline
\end{tabular}

Selanjutnya dilakukan pengujian berbeban dengan potensi angin pada lokasi B maka didapatkan hasil pengukuran untuk pengujian berbeban terlihat pada tabel 2 seperti dibawah ini.

Tabel 2 Pengukuran Berbeban di lokasi B

\begin{tabular}{ccccc}
\hline \multicolumn{5}{c}{ Pengujian Berbeban } \\
\hline $\begin{array}{c}\text { Kec. } \\
\text { Ukur } \\
\text { ke- }\end{array}$ & $\begin{array}{c}\text { Angin } \\
(\mathrm{m} / \mathrm{s})\end{array}$ & Teg. & Arus & $\begin{array}{c}\text { Put. } \\
\text { Gen. }\end{array}$ \\
& & & & \\
& & & & \\
\hline 1 & 5,4 & 9,7 & 1,1 & 159 \\
2 & 5,1 & 9,2 & 1,1 & 148 \\
3 & 5,1 & 9,1 & 1 & 145 \\
4 & 4,1 & 7 & 0,8 & 110 \\
5 & 3,8 & 5,9 & 0,6 & 104 \\
6 & 3,8 & 5,3 & 0,6 & 101 \\
7 & 3,7 & 4,3 & 0,5 & 95 \\
8 & 3,5 & 4 & 0,4 & 59 \\
9 & 3,3 & 3,4 & 0,3 & 53 \\
10 & 3,3 & 2,4 & 0,2 & 49 \\
\hline Rata" & 4,11 & 6,03 & 0,66 & 102,3 \\
\hline
\end{tabular}

Untuk lebih jelasnya disajikan grafik seperti pada gambar di bawah ini. Pada gambar 8 merupakan grafik kecepatan angin pada pengujian tanpa beban terhadap putaran generator, tegangan, dan arus yang dihasilkan. Untuk tegangan dengan tanpa beban diindikasikan berwarna biru sedangkan dengan adanya beban berwarna kecoklatan. Terlihat bahwa semakin rendah kecepatan angin maka tegangan yang hasilkan akan semakin kecil untuk keadaan tanpa berbeban.

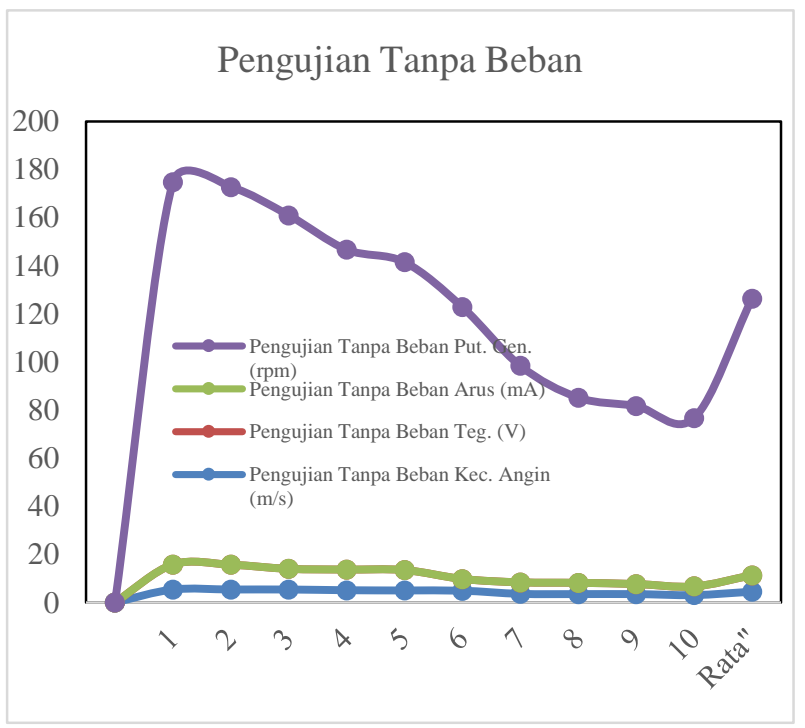

Gambar 8 Pengujian tanpa beban

Selanjutnya pada Gambar 9 merupakan grafik untuk putaran generator yang dihasilkan dalam kondisi berbeban diindikasikan berwarna biru sedangkan dengan adanya beban (accumulator) berwarna hijau Seminar Nasional TEKNOKA ke - 4, Vol. 4, 2019 ISSN No. 2502-8782 
muda. Terlihat bahwa semakin rendah kecepatan angin yang dihasilkan maka semakin kecil untuk keadaan berbeban.

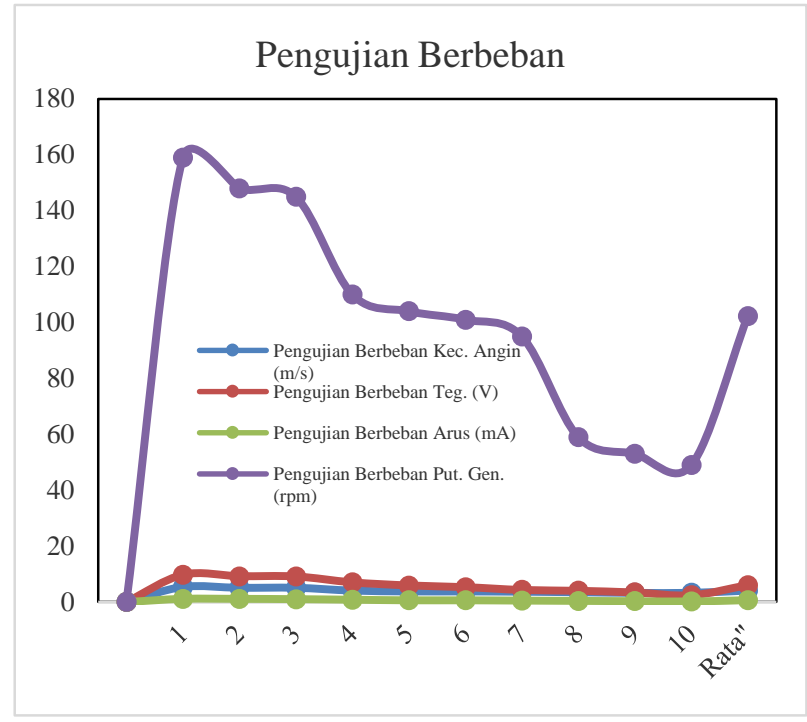

Gambar 9 Pengujian berbeban

Adapun Gambar 10 merupakan ventilator sebagai pembangkit listrik yang telah diuji pada lokasi yang berbeda, namun untuk kelayakan pembangkitan listrik didapatkan lokasi B yang memungkinkan menghasilkan pembangkitan listrik yang optimal.

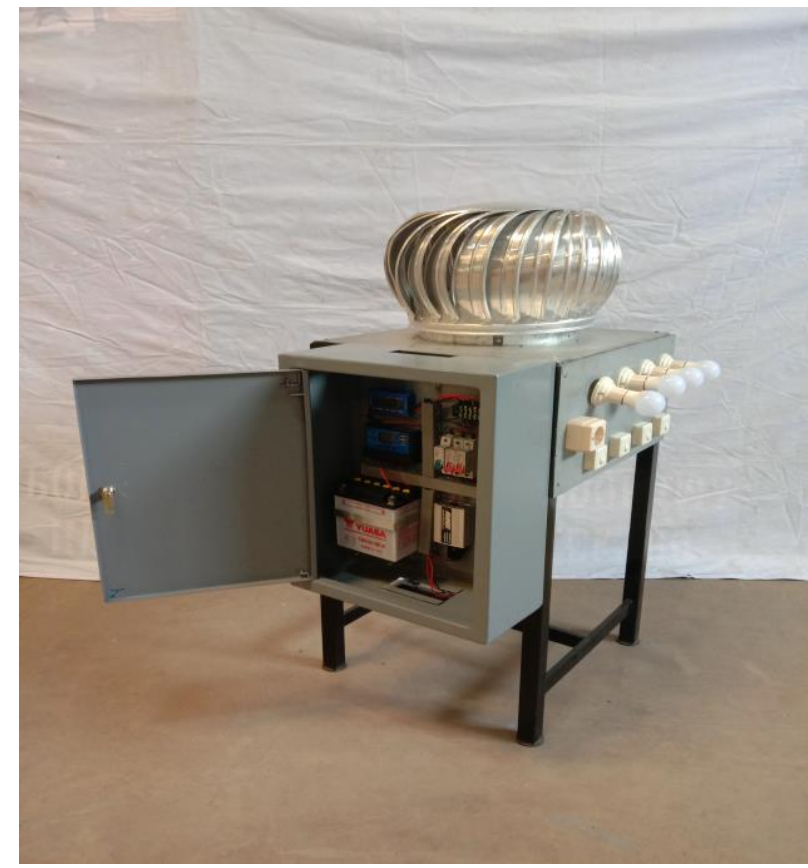

Gambar 10 Ventilator sebagai pembangkit listrik

\section{SIMPULAN}

Pemanfaatan turbin ventilator sebagai pembangkit listrik alternatif mampu untuk menghasilkan pembangkitan listrik pada lokasi pengujian di depan gedung Vocational Training Center. Adapun pengaruh kecepatan angin terhadap tegangan dan arus yang dihasilkan generator, dimana pada kecepatan angin terendah $3,3 \mathrm{~m} / \mathrm{s}$ menghasilkan tegangan $2,4 \mathrm{~V}$ dan arus $0,2 \mathrm{~mA}$ serta pada kecepatan angin tertinggi 5,4 $\mathrm{m} / \mathrm{s}$ menghasilkan tegangan sebesar $9,7 \mathrm{~V}$ dan arus $1,1 \mathrm{~mA}$ dalam keadaan berbeban.

\section{KEPUSTAKAAN}

[1] EK, Laksanawati. 2018. "Analisa Pemanfaatan Turbin Ventilator sebagai sumber listrik skala rumah tangga dengan kapasitas $900 \mathrm{~W}$ ", Tugas Akhir, Program Studi Teknik Mesin, Universitas Muhammadiyah Tangerang.

[2] Kurniadi, Fauzi. 2016. "Pembuatan Turbin Ventilator", Tugas Akhir, Program Studi Teknik Elektro, Politeknik Negeri Padang.

[3] Vivi Nur Huda Lyjamil. 2929. "Pemanfaatan Turbin Ventilator sebagai sumber tenaga listrik",. Skripsi, Departemen Fisika, Institut Pertanian Bogor.

[4] Padmika, Made. 2017. "Perancangan pembangkit listrik tenaga angin dengan turbin ventilator sebagai penggerak generator", Buletin Fisika. Universitas Udayana. 2017: 18 (2): 68-73 https://ojs.unud.ac.id/index.php/buletinfisika/artic le/view/34503

[5] Ismail, M. and Abdul Rahman, A.M. (2012) Rooftop Turbine Ventilator: A Review and Update. Journal of Sustainable Development. 5(5): 121-131. (EBSCO \& ERA Indexed)

http://www.ccsenet.org/journal/index.php/jsd/arti cle/view/14942

[6] Jenny Delly, Wely Likupadang. 2012. "Pemanfaatan Cyclone Turbine Ventilator sebagai Sumber Tenaga Listrik untuk Penerangan Lampu Rumah. 2012 : 4 (1) :

http://ojs.uho.ac.id/index.php/dinamika/article/vi ew/299

[7] Yogasmara, Qorianjaya. 2017. "Perancangan Pulley dan Sabuk pada Mesin Mixer Garam Bleng". Tugas Akhir, Program Studi Teknik Mesin, Universitas Sebelas Maret.

[8] Surya, Andika. 2013. "Makalah Generator DC", Tugas Akhir, Program Studi Teknik Elektro. Universitas Lampung

[9] Setiono Iman, 2015. Akumulator Pemakaian dan Perawatannya. Jurnal METANA. 2015:11(1): 31-36.

http://ejournal.undip.ac.id/index.php/metana/artic le/view/12579 